\title{
Influence of partial reinforcement of running on the extinction of continuously reinforced barpressing in rats*
}

\author{
MICHAEL E. RASHOTTE \\ Florida State University, Tallahassee, Fla. 32306
}

Two experiments with rats show that resistance to extinction of continuously reinforced barpressing is not increased by partial reinforcement of runway running and that, in general, reinforcement manipulations related to one response have little influence on the other.

Generalized partial reinforcement effect (GPRE) describes increased resistance to extinction of a continuously reinforced $(\mathrm{CR})$ response due to experience with partial reinforcement $(P R)$ in other training situations. Brown \& Logan (1965) suggested this terminology and presented some evidence in support of their proposal that the magnitude of the GPRE depends upon the similarity of the stimuli and responses in the CR and PR training situations.

Much of the GPRE literature is consistent with Brown and Logan's proposal about stimulus/response similarity and the GPRE. In several experiments in runways with rats, in which the response in the PR and $C R$ situations was held constant, a maximal GPRE was found (i.e., resistance to extinction of the $\mathrm{CR}$ response equalled that of the $\mathrm{PR}$ response) when the $P R$ and $C R$ situations differed visually (e.g., Amsel, Rashotte, \& MacKinnon, 1966), but not when tactile differences were added to visual (Rudy, Homzie, Cox, Graeber, \& Carter, 1970) or when tactile, spatial, and auditory differences were added to visual (Waters \& Knott, 1970). Other experiments have shown that the GPRE can be weakened by adding response differences to stimulus differences in the $P R$ and $C R$ training situations. For example, the GPRE is maximal when rats are trained to run in visually different situations, but it can be weakened or eliminated by training them to climb in one situation and run in the other (Rashotte, 1968; Ross, 1964), run slow in one situation and fast in the other (Amsel \& Rashotte, 1969; Rashotte \& Amsel, 1968), or turn left to run in one situation and turn right to run in the other (Spear \& Spitzner, 1967).

In view of the procedures that

*This research was supported by a grant from Florida State University. Reprints may be obtained from the author at the Department of Psychology, Florida State University, Tallahassee, Fla. 32306. weakened the GPRE in the experiments reviewed above, it is somewhat surprising that two experiments have been reported which claim to find that, in rats, $P R$ in a runway increases resistance to extinction of $\mathrm{CR}$ barpressing in an operant chamber. In one of these (an
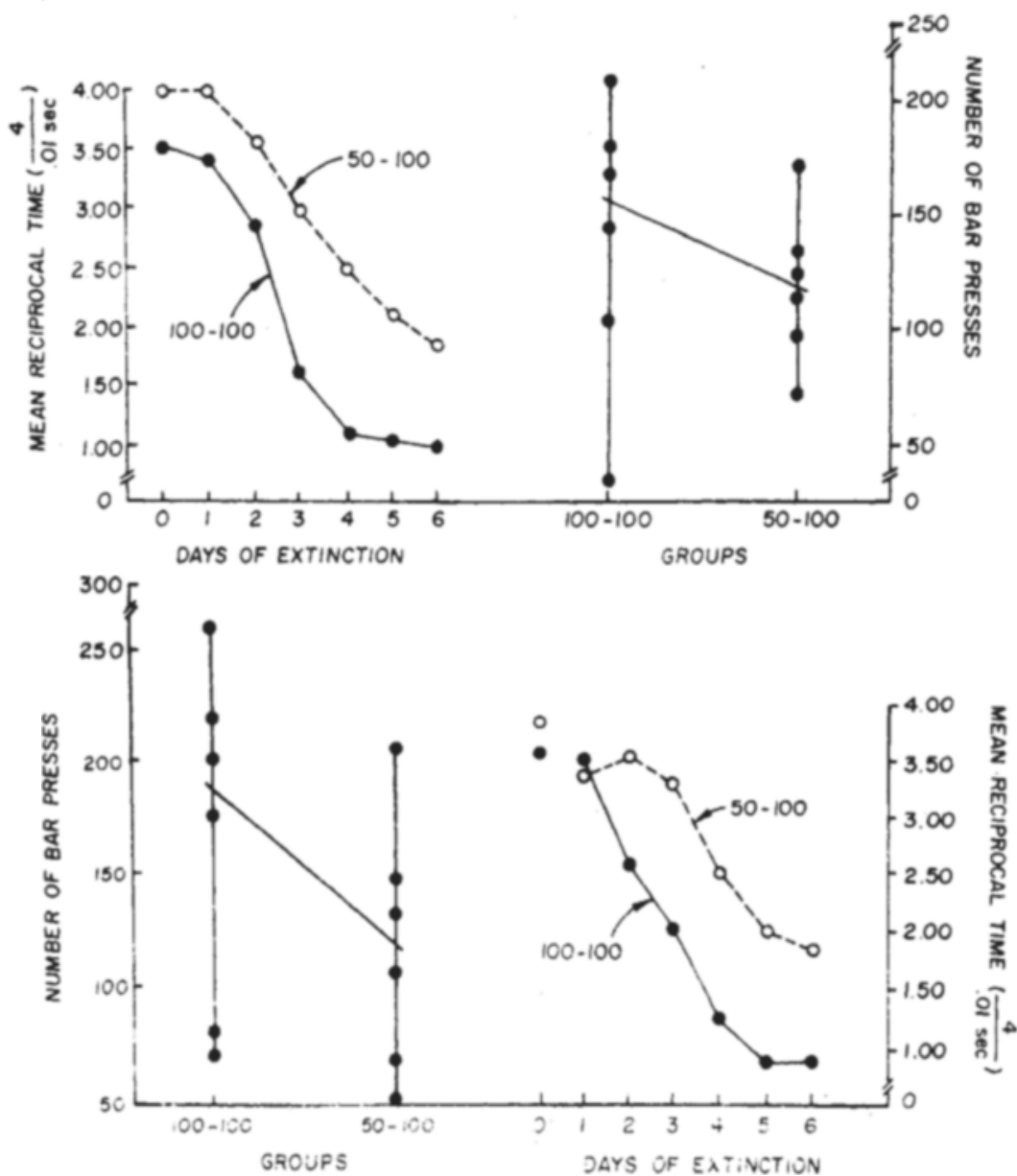

Fig. 1. Extinction of running and barpressing by groups extinguished to criterion on running first and then on barpressing (top panels) and by groups extinguished in the reverse order (bottom panels). The panels showing mean reciprocal time (multiplied by four) as a function of days summarize extinction of running, and the points at Day 0 represent performance on the last day of acquisition. The other panels summarize extinction of barpressing, and each point represents the number of barpresses to criterion for an individual rat. The horizontal line in the barpress panels intersects the median for each group. 
completely the possibility that PR of runway running increases resistance to extinction of CR barpressing.

\section{EXPERIMENT}

\section{Subjects}

The Ss were 24 90-day-old male albino rats of the Sprague-Dawley strain, obtained from Flow Research Animals Inc., Dublin, Virginia.

$$
\text { Apparatus }
$$

Barpress training was given in a Scientific Prototype operant chamber for rats which was equipped with a Lehigh Valley Electronics (Model 1405R) retractable lever and a 97-mg pellet dispenser. Run training was given in a runway $(1.3 \mathrm{~m} \times 73 \mathrm{~mm}$ x $95 \mathrm{~mm}$ ) covered with clear Plexiglas which was entered through an entry box (279 $\mathrm{mm}$ long) and startbox (267 $\mathrm{mm}$ long) in tandem. The entry-start section was the same width and depth as the runway and was painted flat gray. The runway itself was painted flat black on the left side and flat white on the right, in the manner described by Kolesnik \& Amsel (1966). Metal guillotine doors, located between the entry and startboxes and at the entrance to the runway, controlled Ss' movements at the beginning of each trial. When $S$ crossed a photobeam $1.2 \mathrm{~m}$ from the start door, (1) a metal door, $381 \mathrm{~mm}$ from the end wall, was lowered to confine $S$ to the foodcup area for $30 \mathrm{sec}$, (2) one 97-mg Noyes pellet dropped into the recessed foodcup on the end wall if it was a reinforced trial, and (3) a .01 sec clock, which measured running time from the opening of the start door, was disenabled. The operant chamber and runway were situated in the same dimly lighted room, and neither was housed in an enclosure. Control equipment for both apparatuses was in the same room.

\section{Procedure}

The Ss were housed in individual cages under constant illumination with water freely available. In the first 3 weeks at the laboratory, Ss were handled frequently and were fed $10 \mathrm{~g}$ of Purina lab chow at the same time each day. At the beginning of the fourth week, Ss were given 2 days of pretraining in the runway and up to 7 days of pretraining the operant chamber. In runway pretraining, each $S$ was confined in the foodcup area on six separate occasions, four on one day and two on the other. On each confinement, one $97-\mathrm{mg}$ pellet was presented and $S$ was removed when the pellet was consumed. In barpress pretraining, Ss were magazine trained and shaped to barpress until 25 reinforced presses were completed in a single session.

Following pretraining, Ss were assigned to two groups of 12 . During

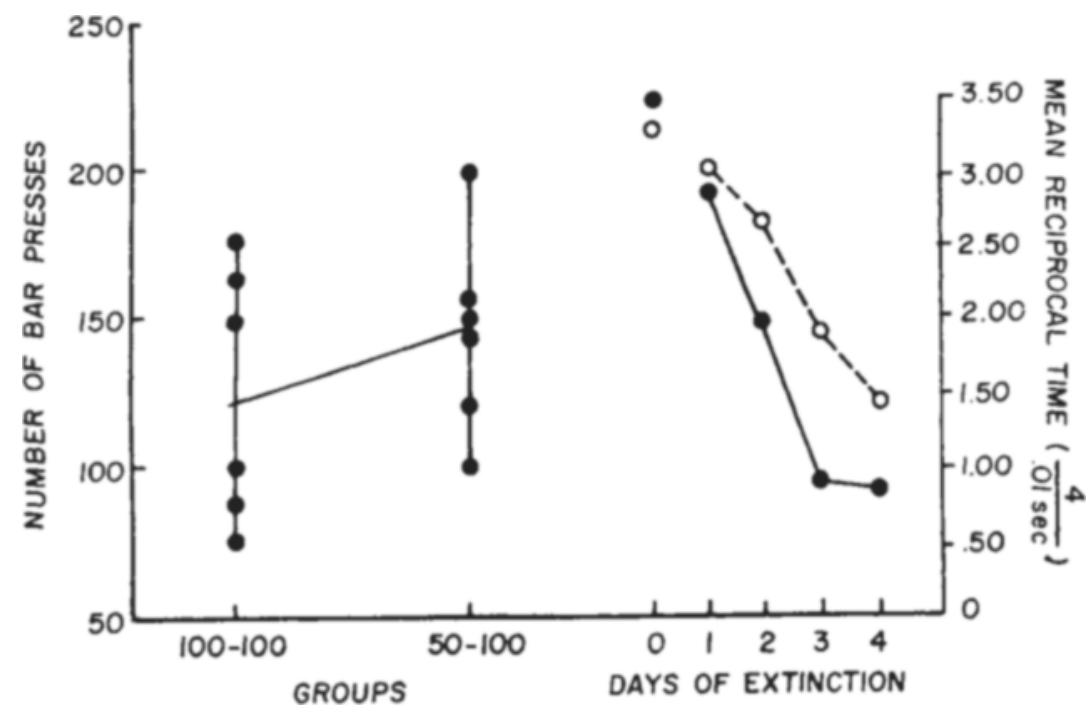

Fig. 2. Extinction of barpressing (left panel) followed by extinction of running (right panel) for groups in Experiment 2. The dotted line in the running panel shows the 50-100 group, the solid line the 100-100 group; the points at Day 0 show performance in the runway on the last day of acquisition. The horizontal line in the barpress panel intersects the median for each group.

acquisition, the $100-100$ group received one $97-\mathrm{mg}$ pellet for each of 25 barpresses per session and one $97-\mathrm{mg}$ pellet on each of 12 runs per running session. The other group, 50-100, was treated in the same way, except no pellet was presented on a random half of its runs in each running session. Barpress (B) and run (R) sessions were conducted on separate days for a 20-day period and occurred in the following order for all rats: BR R B BRBRRBRBRBBRRBRB. At the end of training, each rat had run 120 times and had barpressed 250 times. In B sessions, Ss were brought individually from their home cages and were returned immediately after the session. In $R$ sessions, all $S$ s were brought to the experimental room and were run in rotation. In both $B$ and $R$ sessions, $S$ s were run in an unsystematic order.

Extinction began in the 21st session. Half of each group received daily extinction sessions in the runway until criterion was reached and then was given daily (25 barpresses) extinction sessions in the operant chamber until criterion was reached. The other half of each group received extinction training in the operant chamber first and then was given extinction in the runway. In the operant chamber, criterion was a 60 -sec period without a barpress and each rat's barpress extinction was terminated in the session it reached criterion. In the runway, all Ss were run for six sessions ( 72 trials) and were detained in the foodcup area for $30 \mathrm{sec}$ on each trial. Ss that did not cross the photobeam within $60 \mathrm{sec}$ following the opening of the start door were placed in the foodcup area for $30 \mathrm{sec}$, and a time of $60 \mathrm{sec}$ was recorded on that trial.

Results and Discussion

The panels of Fig. 1 summarize extinction data from the runway and operant chamber. Analysis of variance of the runway data in the upper and lower panels showed a significant overall difference between the $100-100$ and 50-100 groups $[F(1,20)=11.60, \quad p<.01]$, a significant change in performance across days $[F(6,120)=72.34$, $p<.01]$, and a reliable Groups by Days interaction $[F(6,20)=3.22$, $\mathrm{p}<.01]$. These effects indicate that a partial reinforcement effect was obtained in the runway. No reliable main effect or interaction was attributable to the sequence in which running was extinguished (Fs $<1$ ), and this indicates that runway extinction was comparable whether it preceded or followed extinction of barpressing.

Barpress extinction was assessed statistically by Mann-Whitney U tests. The number of barpresses to criterion was not reliably different in the 50-100 and 100-100 groups which received extinction in the operant chamber first (lower left panel of Fig. 1), $U=10.5, p=.16$. There was no reliable difference between the groups for which barpressing was extinguished following extinction of running (upper right panel of Fig. 1), $\mathrm{U}=11, \mathrm{p}=.16$. These comparisons show that $P R$ in the runway did not increase resistance to extincton of barpressing as measured by number of 
responses to criterion. Comparison of the number of barpresses in extinction by the 100-100 groups in the upper and in the lower panel showed no reliable differences, $\mathrm{U}=16, \mathrm{p}=.41$, as did a similar comparison between the 50-100 groups in these panels, $U=15$, $\mathrm{p}=.35$. These comparisons indicate that extinction of barpressing was not influenced by extinction of running.

The results of the present experiment do not agree with the findings of earlier experiments that PR of running increases resistance to extinction of barpressing (Lewis, cited in Spear \& Pavlik, 1966; Wenrich et al, 1967). Rather, the present data argue that, in general, reinforcement manipulations in relation to running do not influence resistance to extinction of barpressing, and vice versa. That is, extinction of barpressing $w$ as not influenced differentially by $P R$ and $C R$ in the runway, and extinction of either response was not influenced by previous extinction of the other.

Although the outcome of this experiment disagrees with the Lewis and the Wenrich et al results, the present experiment differs from those earlier experiments in at least one major respect. In both of the earlier experiments, barpress and run training were given in entirely separate phases, whereas in the present experiment, training of the two responses occurred in an irregular sequence within a single phase. The single-phase procedure was chosen to approximate the conditions of other experiments that have studied the effect of PR of one response on resistance to extinction of another (e.g., Rashotte, 1968). A second experiment was undertaken with a two-phase training procedure.

\section{EXPERIMENT 2}

Two groups ran for 120 PR or CR trials prior to pressing a bar 250 times for $C R$. The barpress response and then the running response were extinguished to criterion for both groups.

The Ss were 12 90-day-old male albino rats obtained from Flow Research Animals Inc. They were maintained under the same conditions as in Experiment 1.

Apparatus and Procedure

The apparatus and the deprivation and handling procedures were the same as those in Experiment 1. As in the first experiment, Ss were assigned to a 100-100 group and a 50-100 group $(\mathrm{N}=6)$ to receive 10 runway sessions of 12 trials each and 10 barpress sessions of 25 presses each. In the present experiment, however, both groups received 10 successive runway sessions and then 10 successive barpress sessions, and both were extinguished to criterion on barpressing before runway extinction was undertaken. All other details of pretraining and training were identical to those of Experiment 1, except that runway extinction lasted for only four sessions.

\section{Results}

The extinction data from this experiment are shown in Fig. 2 and can be summarized easily. There was no reliable difference between groups during extinction of barpressing $(\mathrm{U}=14, \mathrm{p}=.29)$, but analysis of variance showed that during extinction of running there was a reliable change in performance across days $[F(4,40)=64.27, \quad p<.01]$ and $a$ Group by Days interaction $[F(4,40)=3.14, \quad p<.05]$. The significant interaction in this analysis indicates that the PR group extinguished less rapidly than the $C R$ group. That is, PR increased resistance to extinction of running but not of barpressing.

The two experiments reported in this paper show that although runway training with $P R$ increases resistance to extinction of the running response, it does not increase resistance to extinction of a CR barpress résponse learned in training sessions that alternate with, or follow, the runway training sessions.

These results do not agree with the findings of experiments by Lewis (cited in Spear \& Pavlik, 1966) and by Wenrich et al (1967). Rather, the present results support the conclusion that reinforcement manipulations in relation to running do not markedly influence resistance to extinction of barpressing, and vice versa. That is, barpressing extinguished at comparable rates whether the rats had experienced $C R$ or PR of running and whether running had been extinguished or not prior to extinction of the barpress response. In addition, Experiment 1 showed that extinction of running occurred at the same pace whether or not barpressing had already been extinguished. The procedures of the present experiments, then, appear to define training conditions in which the GPRE is absent.

There is no ready explanation for the discrepancy between the present data and the outcomes of the earlier experiments which suggested a GPRE between running and barpressing situations. However, certain aspects of the earlier experiments are inconsistent with a strong argument in their favor: (1) Wenrich et al found only a marginal statistical difference in resistance to extinction of barpressing as a function of PR and CR of running; (2) the finding of Lewis's experiment that the GPRE occurred only when the $P R$ and $C R$ reward was identical (see introduction for details) is inconsistent with Ross's (1964) well-documented finding of a GPRE when reward and deprivation conditions differ between PR and CR training; (3) the earlier experiments did not show that the GPRE they reported in barpressing related in fact to a PRE in running. Not only did the present experiments show that the PRE, which was expected to generalize to barpressing, was present in the running response, they also showed that a PRE in running could be demonstrated after barpressing had been extinguished to criterion. That is, the PRE was "available" during barpress extinction but did not influence resistance to extinction of barpressing.

\section{REFERENCES}

AMSEL, A., \& RASHOTTE, M. E. Transfer of experimenter-imposed slow-response patterns to the extinction of a continuously rewarded response. Journal of Comparative \& Physiological Psychology, 1969, 69, 185-189.

AMSEL, A., RASHOTTE, M, E., \& MackINNON, J. R. Partial reinforcement effects within subject and between subjects. Psychological Monographs, $1966,80(20$, Whole No. 628).

BROWN, R. T., \& LOGAN, F. A. Generalized partial reinforcement effect. Journal of Comparative \& Physiological Psychology, 1965, 60, 64-69.

KOLESNIK, B., \& AMSEL, A. A "split alley" technique for equating brightness in a visual discrimination task. Psychonomic Science, 1966, 5, 187-188.

RASHOTTE, M. E. Resistance to extinction of the continuously rewarded response in within-subject partial-reinforcement experiments. Joumal of Experimental Psychology, 1968, 76, 206-214.

RASHOTTE, M. E., \& AMSEL, A. Transfer of stow-response rituals to the extinction of a continuously rewarded response. Journal of Comparative \& Physiological Psychology, 1968, 66, 432-443.

ROSS, R. R. Positive and negative partial-reinforcement extinction effects carried through continuous reinforcement, changed motivation, and changed response. Journal of Experimental Psychology, 1964, 68. 492-502.

RUDY, J. W., HOMZIE, M. J., COX, R. D., GRAEBER, R. C., \& CARTER, E. N. Effects of sequential manipulations in the within-subjects partial reinforcement runway experiment with rats. Journal of Comparative \& Physiological Psychology, $1970,72,105-115$.

SPEAR, N. E., \& PAVLIK, W. B. Percentage of reinforcement and reward magnitude effects in a $\mathrm{T}$ maze: Between and within subjects. Joumal of Experimental Psychology, 1966, 71, 521-528.

SPEAR, N. E: \& SPITZNER, J. H. PRE within Ss: Conventional effect on differential speeds, reverse effect on choices. Psychonomic Science, 1967, 7, 99-100.

WATERS, W., \& KNOTT, P. D. Tests of frustration theory extended to the generalized PRE. Psychonomic Science, 1970, 20, 61-62.

WENRICH, W. W., ECKMAN, G. E., MOORE, J. J., \& HOUSTON, D. F. A trans-response effect of partial reinforcement. Psychonomic Science, $1967,9,247-248$. 